\title{
COMPARATIVE STUDY OF VISUAL OUTCOME OF EARLY VERSUS DELAYED PARS PLANA VITRECTOMY IN PATIENTS COMPLICATED WITH DROPPED NUCLEUS DURING PHACOEMULSIFICATION
}

\author{
Osman, $\mathrm{H}^{1(*)}$, Elagouz, $\mathrm{M}^{2}$ \& Abd El- badie $\mathrm{M}^{1}$ \\ ${ }^{1}$ Ophthalmology dept., Faculty of Medicine, Al-Azhar Univ., Assiut, Egypt \\ ${ }^{2}$ Ophthalmology dept., Faculty of Medicine, Sohag Univ., Sohag, Egypt \\ *E-mail: hamdy4eye@yahoo.com
}

\begin{abstract}
Purpose: To evaluate the controversy of early and delayed pars plana Vitrectomy (PPV) for posteriorly dislocated lens fragments after phacoemulsification. Patients and Methods: $A$ Prospective study was conducted on all consecutive cases (30 patients) with parsplana Vitrectomy performed for retained lens fragment. In first group: 15 eyes (50\%), PPV were performed within 1 week of cataract extraction and in second group 15 eyes (50\%), PPV were performed more than 1 week post cataract extraction from January 2016 to November 2017. Results: In the first group, $67 \%$ of the patients had a final Visual acuity of 0.3 or better, but $27 \%$ of them achieved a final Visual acuity of 0.5 or better. The mean improvement of Visual acuity in the 1 st week was $0.13 \pm 0.14$, in one month $0.18 \pm 0.16,0.28 \pm 0.21$ in the $3^{\text {rd }}$ month and $0.37 \pm 0.23$ at the end of the 6th month .In the second group, $34 \%$ of the patients had a final Visual acuity of 0.3 or better, but $14 \%$ of them achieved a final Visual acuity of 0.5 or better. The mean improvement of Visual acuity in the 1 st week was $0.09 \pm 0.07$, in one month $0.14 \pm 0.09$, $0.19 \pm 0.13$ in the $3 r d$ month and $0.24 \pm 0.17$ at the end of the $6^{\text {th }}$ month. Conclusions: The visual outcome of the first group in our study is better than that of the second group but with no statistical significance ( $P$ value more than 0.05), the results did not indicate an association between clinical outcomes and whether the patient had an early or delayed PPV, However, there was evidence that early PPV may produce better outcomes than delayed PPV.
\end{abstract}

Keywords: Nucleus loss, Retained lens fragment, Pars plana vitrectomy, Phacoemulsification

\section{Introduction}

As a result of the use of phacoemulsification procedure in cataract surgery, visual outcome and patients convalescence have improved significantly when compared to Extra capsular cataract extraction (ECCE) [1]. However, as a consequence of increased instrumentation and technology in phacoemulsification, surgeons have to face a learning curve to master this technique. As a result of this, there are some complications that are unique to phacoemulsification, the most serious of which is dropped nucleus, or dislocation of the entire nucleus or nuclear fragments into the vitreous cavity during the surgery which can occur at any stage of phacoe- 
mulsification (i.e. during hydro dissection, sculpting or nuclear segment removal) It can even occur during phacoemulsification done by experienced surgeons [2]. Pars plana Vitrectomy (PPV) has been used successfully to retrieve the retained lens fragments in order to minimize the risk of further complications $[3,4]$, although most authors stated that the optimal timing of pars plana Vitrectomy is controversial $[5,6]$ as many studies showed

\section{Patients and Methods}

It was a prospective study including 30 eyes randomly selected presented with nucleus or lens matter loss into the vitreous after complicated cataract surgery (phacoemulsification). The surgical procedure was done from January 2016 to Nov. 2017. They were divided after taking their medical written consent into 2 groups, group A: including 15 eyes underwent Vitrectomy in the same day or within one week from cataract surgery (phacoemulsification) and group B: including 15 eyes underwent Vitrectomy more than 1 week from cataract surgery (phacoemulsification). Follow up data were taken at the 2nd day of surgery, one week and at 1, 3 and 6 month after Vitrectomy for inclusion in the study. The exclusion criteria included those who underwent previous PPV, those with macular lesions such as myopic changes or age related macular degeneration, Patients with ocular Pathology, DME, hypertensive maculopathy, optic atrophy or glaucoma. The parameters of the study included demographics, preexisting eye diseases, details of the previous cataract surgery (including date), performance of anterior Vitrectomy, and intraocular lens (IOL) implantation. In addition, best corrected visual acuity, IOP (considered high, if it was more than $20 \mathrm{~mm} . \mathrm{hg}$, anterior and posterior segment findings at presentation (including the presence of stromal corneal edema, anterior uveitis, lens matter, vitreous and/or fibrin in the anterior chamber, hyphema and hypopyon), the approximate size of that inflammatory reaction caused by the retained lens fragment may be relieved spontaneously or with medications and it may be worsen with longer duration of lens fragments remaining within the eye $[6,7]$. This study evaluated the visual outcome of early and late PPV to manage posteriorly dislocated lens fragments following cataract extraction by phacoemulsification

nuclear fragments in the vitreous, vitritis, vitreous hemorrhage, retinal detachment, CME, and choroidal effusion were evaluated. Other studied variables were the details of the procedure (including date), the interval between cataract extraction and vitreoretinal surgery, use of phacofragmentation (fragmatome) and/or heavy liquids, operative complications such as retinal tear or retinal detachment, final visual acuity, and complications were recorded during the follow-up, A dilated fundus examination was performed preoperatively in order to identify the number and location of the lens fragments, and to rule out any retinal tears or breaks, in which an argon laser photocoagulation was performed if the visualization of the retina was possible. In addition, an IOP was taken, and we noted if there were any other pathologies such as vitreous or suprachoroidal hemorrhage, CME or previous glaucoma. A standard three-port PPV is the procedure of choice using 23 gauage system using a 3 -port transconjunctivalmicrocannulabased 23-gauge PPV system Microcannulas were inserted transconjunctivally, with the help of an insertion trocar, $3.5 \mathrm{~mm}$ posterior to the limbus in the inferotemporal, superotemporal, and superonasal quadrants. A 23-G microvitreoretinal (MVR) blade was inserted tangentially, approximately 30 degrees parallel to the limbus. The infusion cannula was placed in the inferotemporal quadrant, and plugs were used to temporarily close the other entry sites. Any residual lens materials 
surrounding the iris area were carefully removed; care is taken to avoid breaking the capsule remains ready for the final intraocular lens implantation. A core vitrectomy was performed, followed by the removal of the softer cortical lens material and vitreous around the nucleus. A high speed vitrectomy probe with a cutting rate of $1500-2500$ cuts $/ \mathrm{min}$ and a vacuum level of $300-500 \mathrm{mmHg}$ was used during PPV. The balanced salt solution bottle height was set at $50 \mathrm{~cm}$. A bimanual technique was used to push the nucleus into the port of the vitrectomy cutter with the endoilluminator probe. In cases where hard lens material was unable to be removed with the vitrectomy probe, A sclerotomy site was enlarged to accommodate a 20-G MVR blade and the fragmatome hand piece Through this sclerotomy, intravitreal phacoemulsification with a $20-\mathrm{G}$ titanium fragmatome was performed to remove the hard nucleus fragments in the mid-vitreous with a vacuum level of $100-150 \mathrm{mmHg}$. The phacofragmatome tip if needed may be used to aspirate the nucleus material, assisted by the tip of the endoilluminator to keep the nuclear fragments near the phacofragmatome. After the vitrectomy and lensectomy were completed a peripheral examination with scleral depression

\section{Results}

In the first group: 15 eyes of 15 patients were enrolled, 8 of them $(53.30 \%)$ were males, while $7(46.60 \%)$ were females. Their ages varied from 30 to 71 years (mean + SD: $54.2 \pm 11.15$ ) with precataract surgery BCVA $(0.08 \pm 0.06)$ complicated by posterior dislocation of lens matter, tab. (1). The patients underwent PPV, 7 of them $(46.70 \%)$ at the same day, implanting hard PMMA on the ciliary sulcus in 4 cases, 3 piece acrlyic foldable IOL in 2 cases and iris fixating verisyse behind the pupil in one case. The remaining cases (8/15) had a visual acuity ranging from $\mathrm{HM}$ to 0.1 They underwent PPV within aweek, 3 of them (20\%) were complicated by corneal edema is performed, and peripheral vitrectomy was done in order to eliminate any peripheral vitreous traction. If there is any break or tear, an endolaser treatment was done. At the end of the surgery a placement of the IOL was performed in aphakiccases. If a small intact capsulorhexis was present, the IOL can be inserted in the sulcus if PC-IoL was impossible, AC-IOL could be placed. In eyes that received an intraocular lens implantation corneal stromal wound hydration was performed at the end of surgery to ensure water tight secure wounds. If the fragmatomewas used, the 20-G sclerotomy created in the superotemporal quadrant was closed with 7-0 vicryl suture. After the PPV, there was a follow-up control of the patients after one week, one month, three months and six months. The corrected visual acuity was measured at each visit and included in the statistical analysis. Descriptive statistics were calculated using SPSS software (version 13.5). Values are expressed as mean $\pm \mathrm{SD}$, and statistical significance was determined using the Student's t-test for paired data. The McNemar test was used for evaluating the qualitative data such as presence of the CME, corneal edema, retinal detachment and high IOP.

and operated on the $5^{\text {th }}$ day, 3 of them (20\%) were complicated by increase of IOP more than $25 \mathrm{mmhg}$, received antiglaucoma medications and were operated on the $3^{\text {rd }}$ day, while the remaining two cases underwent PPV in the $2^{\text {nd }}$ day after cataract surgery. Five cases $(5 / 8)$ presented with vitreous in $\mathrm{AC}$, two cases (2/8) presented with cortical matter in $\mathrm{AC}$ and one case with vitreous hge, no hypopyon or hyphaema with VA ranging from HM to $3 / 60$. they underwent 23 gauagevitrectomy using a 3-port transconjunctivalmicrocannula-based 23-gauge PPV system, we had to enlarge the port in 5 cases (33\%) for fragmatome use, using PFC for macular protection in 9 cases $(60 \%)$, 
induction of PVD in 9 cases $(60 \%)$, peripheral retinal tear in one case $(6 \%)$. At the end of surgery, we implanted hard PMMA on the ciliary sulcus in 2 cases, and iris fixating verisyse behind the pupil in one case. In the second group: Fifteen patients were entrolled in this group, with pre-cataract surgery BCVA $(0.11 \pm 0.09)$. 6 of them $(40 \%)$ were males, while $9(60 \%)$ were females. Their ages varied from 47 to 75 years (mean + SD: 58.27 \pm 15.34 ). Five cases $33.4 \%$ were complicated by corneal edema, 2 cases $13.4 \%$ by uveitis, 3 cases $20 \%$ with vitreous in AC, 2 cases $13.4 \%$ by choroidal detachment, 4 cases $26.7 \%$ with lensmatter in $\mathrm{AC}$, one case $6.7 \%$ with vitreous haemorrhage and 7 cases $46.7 \%$ with IOP more than 25 mmhg, all received their medications. No hypopyon or hyphaema with VA ranging from $\mathrm{HM}$ to 0.15 (mean $\mathrm{BCVA}$ is 0.085 ). They underwent 23 gauge Vitrectomy using a 3-port transconjunctivalmicrocannula-based 23-gauge PPV system, we had to enlarge the port in 3 cases $(20 \%)$ for fragmatome use, using
PFC for macular protection in 4 cases (26.7\%), induction of PVD in 4 cases (26.7\%), peripheral retinal tears in two cases $(13.4 \%)$ with silicon oil tamponading. In the first group, fig. (1) $67 \%$ of the patients had a final visual acuity of 0.3 or better, but $27 \%$ of them achieved a final visual acuity of 0.5 or better. The mean improvement of visual acuity in the $1^{\text {st }}$ week was $0.13 \pm 0.14$, in one month $0.18 \pm 0.16,0.28 \pm 0.21$ in the $3^{\text {rd }}$ month and $0.37 \pm 0.23$ at the end of the $6^{\text {th }}$ month. The mean IOP, tab. (2) at the $1^{\text {st }}$ month $16 \pm 3.81 \mathrm{mmhg}, 17.75 \pm 5.7$ at $3^{\text {rd }}$ month and $17.45 \pm 5.76$ at the $6^{\text {th }}$ month . In the second group, fig. (1), $34 \%$ of the patients had a final visual acuity of 0.3 or better, but $14 \%$ of them achieved a final visual acuity of 0.5 or better. The mean improvement of visual acuity in the $1^{\text {st }}$ week was $0.09 \pm 0.07$, in one month $0.14 \pm 0.09,0.19 \pm 0.13$ in the $3^{\text {rd }}$ month and $0.24 \pm 0.17$ at the end of the $6^{\text {th }}$ month. The mean IOP, tab. (2) at the $1^{\text {st }}$ month $15.2 \pm 5.08 \mathrm{mmhg}, 14.53 \pm 4.53$ at $3^{\text {rd }}$ month and $16.73 \pm 5.13$ at the $6^{\text {th }}$ month.

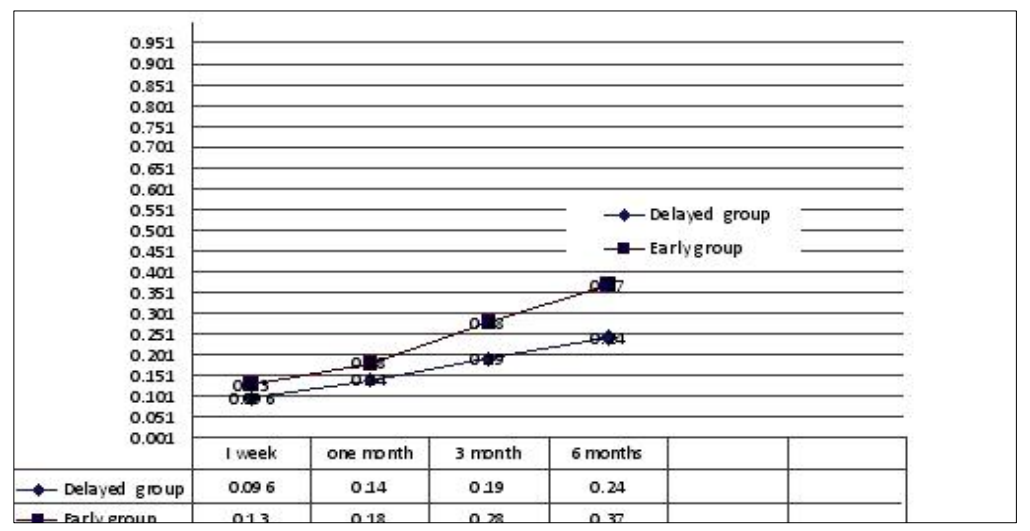

Figure (1): Comparison between the study groups as regards the postoperative BCVA

Table (1) Comparison between the study groups as regards the postoperative BCVA calculated by Log MAR.

\begin{tabular}{|l|c|c|c|c|c|}
\hline \multirow{2}{*}{ Mean BCVA } & \multicolumn{2}{|c|}{ Group A (1 $\mathbf{1}^{\text {st }}$ group $)$} & \multicolumn{2}{c|}{ Group B $\left(2^{\text {nd }}\right.$ group $)$} & P value \\
\cline { 2 - 6 } & Decimal & Log MAR & Decimal & Log MAR & \\
\hline Pre operative mean BCVA & $0.08 \pm 0.06$ & $\mathbf{1 . 0 9}$ & $0.11 \pm 0.09$ & $\mathbf{0 . 9 5}$ & 0.459 \\
\hline BCVA at 1 week & $0.13 \pm 0.14$ & $\mathbf{0 . 8 8}$ & $0.09 \pm 0.07$ & $\mathbf{1 . 0 4}$ & 0.341 \\
\hline BCVA at 1month & $0.18 \pm 0.16$ & $\mathbf{0 . 7 4}$ & $0.14 \pm 0.09$ & $\mathbf{0 . 8 5}$ & 0.403 \\
\hline BCVA at 3month & $0.28 \pm 0.21$ & $\mathbf{0 . 5 5}$ & $0.19 \pm 0.13$ & $\mathbf{0 . 7 2}$ & 0.134 \\
\hline BCVA at 6month & $0.37 \pm 0.23$ & $\mathbf{0 . 4 3}$ & $0.24 \pm 0.17$ & $\mathbf{0 . 6 2}$ & $\begin{array}{c}0.092 \\
\text { (insignificant })\end{array}$ \\
\hline
\end{tabular}


Table (2) Comparison between the study groups as regard postoperative mean IOP.

\begin{tabular}{|c|c|c|c|}
\hline 292999 & Group A (1 ${ }^{\text {st }}$ group) & Group B ( $2^{\text {nd }}$ group) & \\
\hline ????? & Mean \pm SD & Mean \pm SD & P. value \\
\hline IOP1m & $16 \pm 3.81$ & $15.2 \pm 5.08$ & 0.629 \\
\hline IOP3m & $17.8 \pm 5.7$ & $14.53 \pm 4.53$ & 0.084 \\
\hline IOP6m & $17.5 \pm 5.76$ & $16.73 \pm 5.13$ & 0.530 \\
\hline
\end{tabular}

\section{Discussion}

Although PPV is considered the preferred surgical procedure in the management of posteriorly dislocated lens fragments following cataract surgery Flynn HW, et al., found that the patients did not under go PPV after nuclear dropping, their visual acuity deteriorated to counting finger or worse due to chronic complication such a corneal decomposition, glaucoma, RD and optic atrophy, there is a lack of consensus regarding the timing effect of this procedure on the final visual outcome [1]. According to our results of the first group, $67 \%$ of the patients had a final visual acuity of 0.3 or better, but $27 \%$ of them achieved a final visual acuity of 0.5 or better. The mean improvement of visual acuity in the $1^{\text {st }}$ week was $0.13 \pm 0.14$, in one month $0.18 \pm 0.16,0.28 \pm 0.21$ in the $3^{\text {rd }}$ month and $0.37 \pm 0.23$ at the end of the $6^{\text {th }}$ month. In the second group, the mean improveement of visual acuity in the $1^{\text {st }}$ week was $0.09 \pm 0.07$, in one month $0.14 \pm 0.09$, $0.19 \pm 0.13$ in the $3^{\text {rd }}$ month and $0.24 \pm 0.17$ at the end of the $6^{\text {th }}$ month. $34 \%$ of the patients had a final visual acuity of 0.3 or better, but $14 \%$ of them achieved a final visual acuity of 0.5 or better. The results in both groups closely match many other studies[8,9,10] however Greve et al showed $40 \%$ of patients in early Vitrectomy group had vision of 0.4 or higher, but in late vitrectomy group $16.6 \%$ were with vision 0.4 or higher [11,12]. Tasmal et al., [13] and other studies [14-16] concluded that the timing of Vitrectomy did not affect the Visual outcome in respective large series of more than 100 eyes. In contrast, Bolt and his associates 2007 [17] found that
PPV performed within a week after cataract surgery produced inferior outcomes compared with after a week, and recommended, PPV could be delayed until the eye has recovered from cataract surgery. Another study of 89 eyes by Al-Khaier et al., [18] reported that Vitrectomy after 4 weeks statistically correlated with a poor visual outcome, unlike our study in most of the reported series, vitreous surgeries were not performed immediately or on the same day as the cataract surgery, as they did not report the outcome of the 10 patients that received Vitrectomy on the same day. Other large series have failed to demonstrate a statistically significant association between the timing of Vitrectomy and the final visual outcome [8,13-17]. Tommila and Immonen [19] reported that of eyes undergoing Vitrectomy immediately after cataract extraction $57 \%$ of seven eyes achieved a vision of 0.5 or better with a mean 0.43 , compared with $78 \%$ of 16 eyes that were vitrectomized 1-7 days after cataract surgery. Elizabeth AV and his associates in 2014 study found that early PPV was associated with better VA and fewer cases of previtrectomy and postvitrectomy retinal detachment, increased IOP, and intraocular inflamemation/ infection compared with later PPV [20]. Generally the visual outcome of the first group in our study and in many other studies is better than that of the second group but with no statistically significance $[9,10,20]$ ( $\mathrm{P}$ value more than 0.05), the results did not indicate an association between clinical outcomes and whether the patient had an early or delayed PPV, However, there was 
evidence that early PPV may produce better outcomes than delayed PPV, this is may be due to low number of study cases (not conclusive) rather than the variations of amount of retained lens material, course of the eye, details of the manipulations, different complications and timing of the primary cataract surgery, so this study assure the controversy of both procedures with a support for early PPV having superior visual outcomes and less complications by removal the lens fragments before the onset of timedependent inflammation and the accompanying complications, also the same day PPV may take advantage of a clear cornea and minimally inflamed eye to enable better removal of retained lens fragments, with fewer complications, so we recommend further prospective consecutive conclusive clinical trials enrolling large number of patients and a longer follow up period to test a superiority hypothesis comparing of both groups and to provide insight on the proper timing of Vitrectomy. One of the main findings in our study was that the development of secondary glaucoma was observed in about $20 \%$ patients of early Vitrectomy group and $40 \%$ of late Vitrectomy group, the percentage was $30 \%$ and $53 \%$ in Aly et al., [11] study. This means the delay of PPV may double the risk of development of post operative glaucoma in such cases. One of the main findings in Kageyama et al., [21] study is that the development of secondary glaucoma was not observed in any patients. This is in agreement with the findings of Kim et al., [22] in that none of their cases undergoing Vitrectomy for dislocated lens fragments on the same day of cataract surgery developed secondary glaucoma. It was low percentage in our study $1 / 7$ $(14 \%)$ of those done at the same setting. In our study non of the patients of the early PPV developed RD, however incedince of RD in the second group was $13.4 \%$, in Chalam KV and Gupta SK recent study in 2016, The rate of RD in delayed vitrectomy was $21.5 \%$, however their concurrent vitrectomy with identification and laser of retinal tears resulted in prevention of RD. They observed that early vitrectomy removes lens fragments and prevents development of intraocular inflammation and inhibits vitreous contraction, a common cause of retinal tears and detachment. They utilized a $360^{\circ}$ endolaserretinopexy immediately posterior to the vitreous base to reduce the risk of new retinal breaks due to contraction of residual vitreous at the sclerotomy sites, so they suggested a clear benefit of early vitrectomy and barricade laser to eliminate the risk of RD [23].

\section{Conclusion}

The visual outcome of the first group in our study and better than that of the second group but with no statistically significance ( $P$ value more than 0.05$)$, the results did not indicate an association between clinical outcomes and whether the patient had an early or delayed PPV, However, there was evidence that early PPV may produce better outcomes than delayed PPV.

\section{References}

1. Emery, J., Wilhelmus, K., Rosenberg, S. Complications of phacoemulsification. Ophthalmology 1978; 85: 141-150.

2. Scuopla, A., Abed, E., Sammaraco, M., Traina, S. Pars plana vitrectomy for retained lens fragments in complicated cataract surgery. Ophthalmologica 2015; 234 (2): 101-108.

3. Marc, A., Michelson, M. Avoidance, recognition and management, in:
Fishkind, W. (ed.) complications in phacoemulsification, Thieme Medical Publishers, NY, 2002, 123-132.

4. Craig P., Manish N., The dropping and the dropped nucleus, techniques for effective management of fallen fragments, Retina Today 2015; 6: 75-80.

5. Amri, A. Visual outcome of pars plana vitrectomy for retained lens 
fragments after phacoemulsification.

Middle East Afr J Ophthalmol. 2008; 15 (3): 107-111.

6. Vanner, E. Analysis of timing effects of pars plana vitrectomy for removal of intravitreal crystalline retained lens fragments after surgery for agerelated. ClinOphthalmol. 2013; 1 (4): 505-512.

7. Blodi, B., Flynn, H., Blodi, C., Folk, J., Daily, M. Retained nuclei after cataract surgery. Ophthalmology. 1992; 99 (1): 41-44.

8. Orlin, A., Parlitsis, G., Chiu, Y., D'Amico, D., Chan, R., Kiss, S. A comparison of same setting versus delayed vitrectomy in the management of retained lens fragments after cataract surgery. Retina. 2014; 34 (10): 1969-1976.

9. Eifrig, C., Scott, I., Flynn, H., Smiddy, W., Newton, J. Endophthalmitis after pars plana vitrectomy: Incidence, causative organisms, and visual acuity outcomes. Am J Ophthalmol. 2004; 138 (5): 799-802.

10. Rossetti, A., Doro, D. Retained intravitreal lens fragments after phacoemulsification: Complications and visual outcome in vitrectomized and non vitrectomized eyes. J Cataract Refract Surg. 2002; 28 (2): 310-315.

11. Margherio, R., Margherio, A., Pendergast, S., Williams, G., Garretson, B., Strong, L., Trese, M., Cox, M., Hassan, T. Vitrectomy for retained lens fragments after phacoemulsification. Ophthalmology 1997; 104: 1426-1432.

12. Borne, M., Tasman, W., Regillo, C., et al. Outcomes of vitrectomy for retained lens fragments. Ophthalmology. 1996; 103: 971-976.

13. Borne, M., Tasmal, W., Regillo, C., Malecha, M., Sarin, L. Outcomes of vitrectomy for retained lens fragments. Ophthalmology 1996; 103: 971-976.

14. Vilar, N., Jar, H., Smiddy, W., Murray, T., Davis, J., Rubsamen, P. Removal of retained lens fragments after phacoemulsification reverses secondary glaucoma and restores visual acuity. Ophthalmology 1997; 104: 787-792

15. Scott, I., Flynn, H., Smiddy, W., Murray, T., Moore, J., Lemus, D., Feuer, W. Clinical features and outcomes of pars plana vitrectomy in patients with retained lens fragments. Ophthalmology 2003; 110: 1567-1572.

16. Pande, M., Dabbs, T. Incidence of lens matter dislocation during phacoemulsification. J Cataract Refract Surg. 1996; 22: 737-742.

17. Bolt, H., Tajunisah, I., Reddy, S. Dropped nucleus following phacoemulsification cataract surgery. Med J Malaysia 2007; 62 (5): 364-367

18. Al-Khaier, A., Wong, D., Lois, N., Cota, N., Yang, Y., Groenewald, C. Determinants of visual outcome after pars plana vitrectomy for posteriorly dislocated lens fragments in phacoemulsification. J Cataract Refract Surg 2001; 27: 1199-1206.

19. Tommila, P., Immonen, I. Dislocated nuclear fragments after cataract surgery. Eye 1995; 9: 437-441.

20. Elizabeth, A., Michael, W. Metaanalysis comparing same-day versus delayed vitrectomy clinical outcomes for intravitreal retained lens fragments after age-related cataract surgery, Clinical Ophthalmology and Dovi Press Journal. 2014; 8: 2262 -2269.

21. Kageyama, T., Ayaki, M., Ogasawara, M., Asahiro, C., Yaguchi, S. Results of vitrectomy performed at the time of phacoemulsification complicated by intravitreal lens fragments. $\boldsymbol{B} \boldsymbol{r} \boldsymbol{J}$ Ophthalmol. 2001; 85 (9): 1038-1040.

22. Kim, I., Miller, J. Management of dislocated lens material. SeminOphthalmol. 2002; 17: 162-166.

23. Chalam, K. Murthy, P., Priluk, J., Gupta, S. concurrent removal of intravitreal lens fragments after phacoemulsification with pars plana vitrectomy. Int J Ophthalmol. 2015; 8 (1): 89-93. 